УДК

\title{
ТЕОРЕТИЧЕСКАЯ МОДЕЛЬ МАТРИЦЫ ЧУВСТВИТЕЛЫНЫХ ЭЛЕМЕНТОВ В ФОКАЛЬНОЙ ПЛОСКОСТИ QWІР ПРИЕМНИКА ДЛЯ ФОРМИРОВАНИЯ 3D ИЗОБРАЖЕНИЯ В ЛАЗЕРНОМ ЛОКАТОРЕ
}

\author{
МОХАМЕД Б.ЭЛЬ МАШАД, АХМЕД АС-САИД АБУЭЛЬЭЗ \\ Университет аль-Азхар, \\ Ezunem, Kaup, Насер-Сити
}

\begin{abstract}
Аннотация. В статье предложена модель для системы лазерного локатора с трехмерным изображением (3D) и прямым детектированием при использовании матрицы чувствительных элементов в фокальной плоскости (FPA) инфракрасного приемника на квантовых ямах (QWIP). Эту модель предлагается использовать для улучшения формирования 3D изображений на существующих системах теплового (ИК) изображения с одинаковой базовой формой, работающих в средней области инфракрасного диапазона спектра MWIR (3-5 мкм) и в длинноволновой ИК-области спектра LWIR (8-12 мкм). Для получения интегрального сигнала необходимого уровня при коротком времени интегрирования необходима передача лазерных импульсов с высокой энергией и получение фотоэлектронов с энергиями, максимально близкими к тем значениям, которые получены от фоновых фотоэлектронов в системах тепловидения с большим интервалом времени интегрирования. Показано, что поскольку предлагаемая система характеризуется низкими уровнями для спекл-разнесения и высокими уровнями для фотоэлектронов сигнала, то сигнал подчиняется гауссовой функции плотности вероятности. Рассчитанная рабочая характеристика системы для предложенной модели показывает, что для получения удовлетворительных значений параметров необходим приемник с низким темновым током и высокой передаваемой энергией.
\end{abstract}

Ключевые слова: инфракрасный приемник на квантовых ямах; трехмерное изображение; прямое детектирование; ладар; лазерный локатор

\section{1. ВВЕДЕНИЕ}

Технология проектирования запрещенных энергетических зон привела к значительным успехам в разработке новых инфракрасных приемников (ИК). В объемных полупроводниковых материалах электроны свободно перемещаются в любом из трех пространственных направлений. Ограничивающая структура выполняется путем встраивания ограниченной области одного материала внутрь другого. Разница между разрешенными электронными состояниями двух материалов образует барьер для свободного перемещения электронов. Если любое измерение этой структуры при- ближается к длине волны электрона, это приводит к возникновению квантовых эффектов. Квантовые структуры полупроводниковых материалов обладают свойством ограничения подвижности электронов.

Каждое из трех измерений объемного материала может быть удалено из рассмотрения, что приводит к упрощению и получению трех классов квантовых структур. Упрощение структуры вдоль одной оси приводит к двумерному слою, который называется квантовой ямой. Если упрощение осуществляется вдоль двух осей, создается одномерная квантовая проволока. Упрощение вдоль трех осей приво- 